Faculty of Nursing and Midwifery, Royal College of Surgeons in Ireland, Dublin, Ireland

2 Centre for Nursing and Midwifery Advancement, Faculty of Nursing and Midwifery, Royal College of Surgeons in Ireland, Dublin, Ireland

Correspondence to: P Mahon pmahon@rcsi.ie

Cite this as: $B M J$ 2021;373:n1232

http://dx.doi.org/10.1136/bmi.n1232

Published: 14 June 2021

\title{
THE FUTURE OF NURSING
}

\section{How to attain gender equality in nursing-an essay}

\section{Tackling stereotypes and assumptions that deter men from nursing is essential to meet the growing} shortage of nurses and improve diversity, say Thomas Kearns and Paul Mahon

\section{Thomas Kearns, ${ }^{1}$ Paul Mahon ${ }^{2}$}

The covid-19 pandemic shows that where, when, how, and to whom care is delivered has never been more diverse. In today's healthcare, the people delivering care must be similarly diverse, for the benefit of the profession, its practitioners, and patients. ${ }^{1-3}$ Yet around $90 \%$ of the world's nurses are women. ${ }^{4}$ Calls are being made, as they have before, to examine ways to promote the profession among men to tackle this imbalance. ${ }^{15}$

Nursing is an inherently human experience: it is done for humans, by humans, and as humans, and in human experience no one gender claims primacy. Men have had, and continue to have, a valuable contribution to make to nursing, not simply because they are male but because they are human. Men enter the profession for the same reason as women-to care for people.

\section{Huge shortage}

Nurses are often the first, and sometimes the only, healthcare provider that a patient sees, ${ }^{6}$ making them well positioned to respond to healthcare challenges at every level. One of the key challenges affecting the achievement of the sustainable development goals of health and wellbeing, ${ }^{7}$ is the worldwide shortage of nurses. Recruiting more men is essential to tackle this shortage.
The world faces a deficit of 13.5 million nurses in the next decade.$^{4}$ In its first report on the state of the world's nursing, ${ }^{6}$ the World Health Organization estimated that an additional six million nurses will be needed by 2030 . This is a $20 \%$ increase from the current total global nursing stock of 27.9 million. In addition, the burden of anticipated retirement over the next decade means that 4.7 million new nurses must be recruited just to maintain current staffing levels. ${ }^{4}$ It is too early to say what effect the covid-19 pandemic will have on intention to join the profession, but initial estimates are that at least a further $10 \%$ will leave. ${ }^{9}$ Data to monitor the effect of covid-19 on recruitment and retention of nurses will be vital.

Recent changes in society, healthcare globally, and nursing have seen more men entering the profession. In general, their number varies across regions (table 1) and remains stubbornly low in some countries and clinical specialties such as obstetrics. ${ }^{10}$ The reasons for this are unclear but may include cultural perceptions of the role of men and women in society, the status of nursing itself, or the pay and conditions of nurses. For example, a higher proportion of male nurses in some countries may reflect societal perceptions of the role of women, and vice versa. Further research into this area may provide useful insights into gender equity for all.

Table 1 | Percentage of male nurses worldwide*

\begin{tabular}{lcc} 
Region & Regional mean (\%) & Range among countries (\%) \\
African region & 38 & $8-90$ \\
\hline American region & 11 & $2-24$ \\
\hline Eastern Mediterranean region & 26 & $9-56$ \\
\hline European region & 11 & $0-32$ \\
\hline South-east Asia region & 18 & $0-62$ \\
\hline Western-Pacific region & 18 & $2-40$ \\
\hline
\end{tabular}

* National Health Workforce Data Portal (https://apps.who.int/nhwaportal/Home/Index). Year of data varies by country from 2009 to 2019

\section{Why are men under-represented?}

Contrary to the common perception that male nurses are a relatively recent phenomenon, men in nursing can be traced to $1600 \mathrm{BC}$ (box 1$).{ }^{16}$ History speaks of military and religious orders such as the Parabalani ("those who disregard their lives")-a group of men who cared for people with leprosy in Alexandria in AD416, or St Camillus de Lellis, who in AD1535 vowed to care for sick and dying people. ${ }^{512}$ The Maltese cross, a symbol of humanitarianism worn by the Knights Hospitaller in 1099, was subsequently adopted by the Nightingale School of Nursing in London. ${ }^{14}$

\section{Box 1: Brief history of men in nursing}

- 250BC: First nursing school in the world started in India. Only men were considered "pure" enough to become nurses ${ }^{11} 12$ 
- AD416-18: The Theodosian codes refer to the Parabolani-a group of 500 poor men who cared for the lepers of Alexandria 512

- 1095: Order of the Brothers of St Anthony founded (merged with the Knights of Malta in 1775) to care for people inflicted with the medieval disease of St Anthony's fire ${ }^{13-15}$

- 1099: Knight Hospitallers of St John of Jerusalem founded to care for sick and injured pilgrims en route to and from the Holy Land ${ }^{13} 15$

- 1119: Order of Saint Lazarus of Jerusalem founded

- 1180: Order of the Hospitallers of the Holy Spirit and the Brotherhood of the Holy Spirit founded

- 1192: Order of Brothers of the German House of Saint Mary in Jerusalem, or the Teutonic Knights, founded

- 1334: The Beghards (renamed Alexian Brothers after Saint Alexis in 1469) cared for the poor, the lepers, and the "morons and lunatics" of Europe 51416

- 1535: St John of God began studying under the monks of St Jerome and cared for the ill and mistreated

- 1585: St Camillus de Lellis became a priest and established a religious order, vowing to care for the sick and dying even with danger to his own life

- 1600s-1700s: Protestant reformation led to the closure of monasteries and convents across Europe resulting in a loss of records of organized nursing activity ${ }^{14} 16$

- 1780s: Nurse James Durham (or Derham) became the first African American in the United States to practise medicine ${ }^{12}$

- 1850-1950s: War began to alter nursing, and the role of men within it

- 1859: Florence Nightingale publishes Notes on Nursing, suggesting "every woman is a nurse"

- 1861-65: American civil war: more women became nurses in civilian life $\mathrm{e}^{12}$

- 1877: St John Ambulance Association founded (derived from the Knight Hospitallers)

- 1884: The Male Nurses (Temperance) Cooperation founded

- 1892: The Male Nurses Mutual Benefit Association founded

- 1888-1914: Alexian Brothers and other orders built hospitals throughout Chicago, Connecticut, Massachusetts, Missouri, New York, and Pennsylvania. Increasingly, men became nurses at their own social peril, experiencing discrimination, pay inequality, role erosion, and exclusion from formal nurse education ${ }^{2} 17$

- 1914-18: American men were prohibited from practising in the US Army Nursing Corps

- 1919: The Nurses Act in England barred men from entering the general register. 5111415 Internationally, men found it difficult to access formal training and where they did, their training was shorter and lacked the curricular content of their female counterparts 515

- 1937: Society of Registered Male Nurses founded

- 1950s: Men begin to be recognized in nursing in the US, Czechoslovakia, the UK, ${ }^{2} 14$ and towards the 1970 , in Denmark and Sweden ${ }^{15}$

- 1971: American Assembly for Men in Nursing founded

By the mid-18oos as men fought and died during the Crimean, American civil, and other wars, more women became nurses. In the years after the introduction of the epochal Nightingale reforms, men were increasingly excluded from formal nurse education and eventually were barred from the English general register. ${ }^{2511141517}$
Combined with the gender based division of labor, and Victorian righteousness regarding the place of women in society, ${ }^{14-16} 18$ the feminization of caring within the hierarchical male dominated medical model meant men wishing to do the dirty "women's work" were classified as deviant, undesirable, or unable to get a "real man's" job. As caring became devalued, more men were forced to find occupations with better pay so they could provide for their families. ${ }^{16}$

The decline of the male nurse is a complex product of cultural, historical, economic, and political factors. In modern times, the move from the hospital based apprenticeship model of education to the tertiary setting has helped establish nursing as a profession. But rising entry requirements have not been accompanied by a corresponding increase in remuneration, making nursing a less attractive career option for men and women. In addition, gendered and inaccurate representations of nursing and male nurses limit the public's perception and affect the recruitment and retention of men. ${ }^{319}$

Men in the profession have also experienced stigmatization and have been disparately positioned as being both dominant and dominated, victimized and valorized, and of benefiting from the hidden advantages of status shield and status bonus that their gender affords. ${ }^{20} 21$

Studies show that adverse stereotypes affect male nurses' physical and emotional wellbeing, resulting in depression, demotivation, and in some cases their exit from the profession. ${ }^{19}$ The perpetuation of such stereotypes and gender based labels injures the profession, preserves segregation, and stifles the pursuance of gender equality for all. ${ }^{1622}$ Moreover, they compound the shortage of nurses, limit diversity in the workplace, and deny patients of both genders a holistic caring environment. ${ }^{1523}$

\section{What can be done?}

Increasing the number of men in nursing is seen as difficult because of the erroneous perception that nursing is a female-only profession, sexist stereotypes of the male nurse being less masculine, ${ }^{11} 1316$ and nurses' undervalued status and pay. Solutions are as complex as the genesis of the 200 year decline of men in nursing. There is no quick fix, and change requires political, sociocultural, and professional action. Although some solutions will be universal, ultimately each country and culture will have to determine what works best for them. Nurse leaders and politicians should offer long term, strategic solutions beyond mere marketing campaigns. ${ }^{3}$

\section{Better public understanding}

That is not to say that marketing is not needed. Indeed, given the publicity afforded to the profession during the pandemic, now is an ideal time to set aside the nostalgic view of nursing ${ }^{3}$ and capitalize on a contemporary civic conception of caring, competence, and capability throughout clinical settings from community to critical care.

The public has seen nurses caring for ventilated patients, using tablet computers so that family members could say goodbye to loved ones, leading covid testing centres, and innovating in practice. We have heard stories of nurses' adaptability, resilience, determination, camaraderie, and composure. We have seen them hold patients' hands and hold governments to account while fighting for proper personal protective equipment. This has given the public a better insight into the art and science of caring in modern healthcare, which we can build on to attract more men, and women, to the profession. 
Neither patients nor the public fully understand the complexity of nurses' work. ${ }^{3}$ Highlighting nurses' roles across domains of practice, registration status, and stage of career could promote a more realistic understanding, not just of men in nursing but of nursing itself. ${ }^{24}$ Campaigns such as Nursing Now have raised the status and profile of nursing, and this momentum must be maintained. As part of this, we must de-gender and revalue caring ${ }^{1}$ by attaining a gender balance and by continuing to advocate for better pay and conditions for nurses. ${ }^{25}$

\section{Better recruitment}

Men enter and stay in nursing for many of the same reasons as women, and ultimately, they do so to care for patients. ${ }^{24}$ Therefore, recruitment strategies that dispel the myths surrounding the male nurse while promoting the inherent values of nursing are needed. ${ }^{10}$ We can look to countries with higher percentages of male nurses for direction.

For men becoming nurses mid-career, graduate entry should be an option-not just in terms of access to a place on the program but also with financial support to facilitate the uptake of that place. As countries seek to increase the number of nursing graduates, consideration could also be given to a specific allocation of places to male applicants to show that men are both missing and needed in nursing. ${ }^{17}$ Many male nurse societies were established in the mid-18oos, and such social supports, including the provision of male role models, will help retain men in the profession.

\section{More financial investment}

WHO recommends that nursing education be considered a science subject. ${ }^{6}$ Therefore, nursing should be afforded the status, pay, and benefits of other science and technology professions. For example, a senior staff nurse (a nurse with over 20 years' experience) in Ireland earns just under $€ 50$ ooo ( $€ 43$ 000; \$61 000) in base pay a year whereas a pharmacist earns the same after seven years and up to $€ 67$ ooo after 13 years. ${ }^{26}$

Adequate pay and acceptable working conditions, ${ }^{6}$ mobility, and opportunity for personal and professional advancement must underpin and be highlighted in recruitment and retention initiatives.

\section{Confrontation of stereotypes}

Stereotypical assumptions must be challenged at school and societal level in careers guidance, mainstream and social media, and popular culture so that boys know that nursing is a valid career option. ${ }^{31927-29}$ This will require greater intersectoral and cross government collaboration from the early years to higher education levels, ${ }^{6}$ and for broadcasters to consider how their programming may negatively portray nursing and male nurses. We must robustly voice our objection to any outdated overtures that disenfranchise the profession and the people within it.

We must also promote professional acceptance and challenge stereotypes and assumptions in the profession itself-such as those in relation to male nurses' sexuality, ability to care, or reasons for entering the profession. For example, the literature often refers to the "hidden advantage" of male nurses and the over-representation of men in leadership positions without examining broadly why this is so.

Although there may be many individual and institutional reasons for this "glass elevator," including conscious and unconscious bias, hegemonic masculinity, explicit or tacit discrimination, continuity of employment, organizational gendering practices, or the personal and professional characteristics of the individual nurse,${ }^{173031} \mathrm{such}$ discussion conflates the problem of attracting men to the profession with the career progression of all nurses. Indeed, examining ways to empower all nurses thorough initiatives such as the International Council of Nurses' global nurse consultants initiative will help improve health, promote gender equality, and support economic growth. ${ }^{32}$

\section{Continuing men's long history in nursing}

Men have a rich and varied history in nursing, a history that is somewhat lost to the last 200 years and the often misquoted preface of Florence Nightingale's Notes on Nursing that "every woman is a nurse." Less well quoted, however, is her full contention that "While it has been said and written scores of times, that every woman makes a good nurse I believe, on the contrary, that the very elements of nursing are all but unknown.”

The consequences of the lack of men in nursing can be considered in terms of the effect on male nurses themselves, the profession as a whole, and on the patients that nurses serve.

To increase the number of men in nursing, it is important to highlight to men their historical past and their potential future in a rewarding, contemporary career with myriad clinical, academic, and professional development opportunities. The profession must continue to lobby governments to move beyond mere platitudes and actually provide parity of pay and esteem. We must portray to the public the true scope and complexity of our professional practice, ${ }^{3}$ and we must build a profession for all through robust policy that focuses on education, jobs, practice, and leadership.

Competing interests: We have read and understood BMJ policy on declaration of interests and declare that we have no competing interests.

\section{Provenance and peer review: Commissioned; externally peer reviewed.}

This article is part of a series commissioned by The BMI for the World Innovation Summit for Health (WISH). The BM/ peer reviewed, edited, and made the decision to publish. The series, including open access fees, is funded by WISH.

Sasa RI. Male nurse: a concept analysis. Nurs Forum 2019;54:593-600. doi: 10.1111/nuf.12374 pmid: 31463944

2 Bonair J, Philipsen N. Men in nursing: addressing the nursing workforce shortage and our history. Md Nurse 2009;10:19.

3 Girvin J, Jackson D, Hutchinson M. Contemporary public perceptions of nursing: a systematic review and narrative synthesis of the international research evidence. J Nurs Manag 2016;24:994-1006. doi: 10.1111/jonm.12413 pmid: 27406529

4 Buchan J, Catton H. Covid-19 and the international supply of nurses: Report for the International Council of Nurses. International Council of Nurses, 2020.

Arif S, Khokhar S. A historical glance: challenges for male nurses. J Pak Med Assoc 2017;67:1889-94.pmid: 29256536

6 World Health Organization. State of the world's nursing 2020: investing in education, jobs and leadership. WHO, 2020.

Jensen L, ed. The sustainable development goals report 2020. United Nations, 2020

8 Petges N, Sabio C. Perceptions of male students in a baccalaureate nursing program: a qualitative study. Nurse Educ Pract 2020;48:102872. doi: 10.1016/j.nepr.2020.102872 pmid: 32891926

9 International Council of Nurses. Mass trauma experienced by the global nursing workforce. ICN Covid update 13 Jan 2021. https://www.icn.ch/sites/default/files/inlinefiles/ICN\%20COVID19\%20update\%20report\%20FINAL.pdf

10 Twomey JC, Meadus R. Men nurses in Atlantic Canada. J Men's Stud 2016;24:78-88doi: 10.1177/1060826515624414

11 Mahon P, Cowman S. The male nurse: a historical and contemporary analysis of the literature. All Ireland Journal of Nursing and Midwifery. 2003;2:34-9.

12 Wilson B. A history of men in American nursing. Nebr Nurse 2003;(Sept-Nov):15-6.

13 Smallheer B, Morgan B, Stern R. A historical look at men's involvement in nursing and leadership in GAPNA. Geriatr Nurs 2020;41:52-3. doi: 10.1016/j.gerinurse.2020.01.003 pmid: 32044147

14 Evans J. Men nurses: a historical and feminist perspective. J Adv Nurs 2004;47:321-8. doi: 10.1111/j.1365-2648.2004.03096.x pmid: 15238127

15 Clementson R. Men in nursing. Nurs J (Manila) 2008;(12):37-43.

16 Mackintosh C. A historical study of men in nursing. J Adv Nurs 1997;26:232-6. doi: 10.1046/j.1365-2648.1997.1997026232.x pmid: 9292355

17 Cottingham M. The missing and needed male nurse: DIScursive hybridization in professional nursing texts. Gend Work Organ 2019;26:197-213doi: 10.1111/gwao.12333. 
18 Hase S. The role of the man in nursing. Aust Nurses /1977;7:52-3, 80.pmid: 242528

19 Rabie T, Rossouw L, Machobane BF. Exploring occupational gender-role stereotypes of male nurses: A South African study. Int J Nurs Pract 2020:e12890. doi: 10.1111/ijn.12890 pmid: 32964584

20 Santos M, Amâncio L. Gender and nursing in Portugal: the focus on men's double status of dominant and dominated. Int J Iberian Stud 2019;32:159-72doi: 10.1386/ijis_00003_1

21 Cottingham M, Erickson R, Diefendorff J. Examining men's status shield and status bonus: how gender frames the emotional labor and job satisfaction of nurses. Sex Roles 2015;72:377-89doi: 10.1007/s11199-014-0419-z

22 All Party Parliamentary Group on Global Health. Triple impact: how developing nursing will improve health, promote gender equality and support economic growth. All Party Parliamentary Group on Global Health, 2016

23 Younas A, Sundus A, Zeb H, Sommer J. A mixed methods review of male nursing students' challenges during nursing education and strategies to tackle these challenges. J Prof Nurs 2019;35:260-76. doi: 10.1016/j.profnurs.2019.01.008 pmid: 31345506

24 Stanley D, Beament T, Falconer D, etal. The male of the species: a profile of men in nursing. J Adv Nurs 2016;72:1155-68. doi: 10.1111/jan.12905 pmid: 26799533

25 International Council of Nurses. ICN says nurses' pay and safety are gender issues at the United Nations Commission on the Status of Women (CSW65) virtual event. Press release, 22 Mar 2021. https://www.icn.ch/sites/default/files/inline-files/WS_09_CSW65_final_FINAL.pdf

26 Health Service Executive. Health sector consolidated salary scales in accordance with FEMPI 2015 and the public service stability agreements 2013-2020 (The Lansdowne Road Agreements). 2020. https://healthservice.hse.ie/filelibrary/staff/october-2020-consolidated-pay-scales.pdf

27 N'Gbichi C, Ziraba AK, Wambui DW, etal. "If there are no female nurses to attend to me, I will just go and deliver at home": a qualitative study in Garissa, Kenya. BMC Pregnancy Childbirth 2019;19:332. doi: 10.1186/s12884-019-2477-2 pmid: 31500582

28 Kalemba J. 'Being called sisters': masculinities and black male nurses in South Africa. Gend Work Organ 2019;27:647-63doi: 10.1111/gwao.12423

29 Dos Santos L. Male nursing practitioners and nursing educators: the relationship between childhood experience, social stigma, and social bias. Int J Environ Res Public Health 2020;17:4959.doi: 10.3390/ijerph17144959

30 Brown C, Jones L. The gender structure of the nursing hierarchy: the role of human capital. Gend Work Organ 2004;11:1-25doi: 10.1111/j.1468-0432.2004.00218.x

31 Turkmen B, Eskin Bacaksiz F. Does the glass elevator still work: a descriptive and cross-sectional study in the context of gender in Turkey. J Nurs Manag 2021. doi: 10.1111/jonm.13266 pmid: 33484591

32 ICN Certified global nurse consultants. https://www.icn.ch/what-we-do/icn-certified-global-nurseconsultants

This is an Open Access article distributed in accordance with the Creative Commons Attribution Non Commercial (CC BY-NC 4.0) license, which permits others to distribute, remix, adapt, build upon this work non-commercially, and license their derivative works on different terms, provided the original work is properly cited and the use is non-commercial. See: http://creativecommons.org/licenses/bync/4.0/. 